\title{
SOSIALISASI TEKNOLOGI PENGOLAHAN CITRA SECARA DARING SEBAGAI UPAYA PENCEGAHAN MANIPULASI BANTUAN SOSIAL DI HAIBAGEUR.COM
}

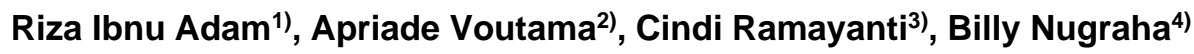 \\ 1)Program Studi S-1 Teknik Informatika, Fakultas IImu Komputer, Universitas Singaperbangsa Karawang, Karawang, \\ Jawa Barat, Indonesia \\ 2)Program Studi S-1 Sistem Informasi, Fakultas IImu Komputer, Universitas Singaperbangsa Karawang, Karawang, \\ Jawa Barat, Indonesia \\ 3) Jurusan Teknik Kimia, Politeknik Negeri Sriwijaya, Palembang, Sumatera Selatan, Indonesia \\ 4)Program Studi S-1 Teknik Industri, Fakultas Teknik, Universitas Singaperbangsa Karawang, Jawa Barat, Indonesia \\ Corresponding author : Riza Ibnu Adam \\ E-mail : riza.adam@staff.unsika.ac.id
}

\section{Diterima 01 April 2021, Direvisi 17 April 2021, Disetujui 17 April 2021}

\begin{abstract}
ABSTRAK
Haibageur.com merupakan sebuah aplikasi digital yang bergerak dibidang sosial. Aplikasi ini bertujuan untuk memberikan bantuan kepada masyarakat terdampak Covid-19 melalui toko klontong di sekitarnya. Akan tetapi banyak toko klontong yang memanipulasi beras bantuan yang ditetapkan, sehingga kualitas beras bantuan menjadi menurun. Oleh karena itu perlu adanya upaya untuk meminimalisir manipulasi beras tersebut. Maka tujuan dari kegiatan pengabdian ini adalah untuk memberikan edukasi kepada masyarakat, khususnya yang memiliki usaha. Teknologi pengolahan citra adalah salah satu upayanya. Adapun tahapan dalam menerapkan teknologi tersebut adalah sosialisasi, pendampingan dan diskusi. Maka metode pelaksanaan yang sesuai dengan cara pelatihan dan pendampingan secara berkala. Seluruh tahapan pelaksanaan kegiatan pengabdian ini dilakukan secara daring. Hasil akhir dari kegiatan ini berupa alat identifikasi jenis beras yang dapat diterapkan di Haibageur.com sebagai mitra utama.
\end{abstract}

Kata kunci: identifikasi beras; pengolahan citra; pengabdian daring; manipulasi bantuan sosial.

\begin{abstract}
Haibageur.com is a digital application engaged in the social field. This application aims to provide assistance to the people affected by Covid-19 through the surrounding groups. However, many clontong shops manipulate the rice assistance set, so the quality of rice help has decreased. Therefore, there needs to be an effort to minimize the manipulation of rice. Then the purpose of this service activity is to provide education to the community, especially those who have a business. Citra processing technology is one of its efforts. The stages in implementing these technologies are socialization, assistance and discussion. Then the method of implementation is in accordance with the way of training and mentoring regularly. All the stages of implementing this service activity carried out online. The final result of this activity is a type of rice identification tool that can be applied in Haibageur.com as the main partner.
\end{abstract}

Keywords: rice identification; image processing; devotion online; manipulation of social assistance.

\section{PENDAHULUAN}

Haibageur.com merupakan sebuah platform digital yang bertujuan untuk membantu masyarakat yang terdampak secara ekonomi akibat pandemi Covid-19 (Candra, et al., 2021). Platform ini bekerja dengan cara menyalurkan bantuan dari para donator ke masyarakat terdampak melalui toko klontong disekitar mereka. Alur tersebut dibuat agar kegiatan ekonomi toko klontong juga dapat berputar, sehingga bukan hanya masyarakat yang membutuhkan saja yang dapat menerima manfaat tersebut. Disamping itu, pemilik toko klontong juga dapat berpartisipasi langsung dengan mendata masyarakat disekitarnya yang terkena dampak. Sehingga proses penyaluran bantuan bisa lebih cepat dan akurat (Poernomo \& Melita, 2013; Priadana \& Murdiyanto, 2019; Putri, 2016). Bantuan yang disalurkan umumnya berupa beras, telur dan minyak goreng, dimana bantuan tersebut dipersiapkan dan distribusikan oleh pemilik toko klontong. Selanjutnya Haibageur.com akan mentransfer sejumlah uang yang sesuai dengan paket bantuan yang telah disalurkan kepada pemilik toko klontong. Akan tetapi ada beberapa toko klontong yang menyalurkan bantuan namun tidak sesuai dengan spesifikasi yang ditentukan oleh Haibageur.com. Salah satu bentuk bantuan yang sering dimanipulasi oleh toko 
klontong adalah beras. Beras menjadi komoditas yang sering dimanipulasi karena sulitnya membedakan dan banyaknya jenis beras yang beredar (Saputra, et al., 2019; Oktonius, et al., 2014).

Pandemi Covid-19 menyebabkan terbatasnya kegiatan pemantauan kualitas paket bantuan oleh Haibageur.com. Sehingga diperlukan sebuah teknologi yang mampu melakukan monitoring tanpa harus bertemu langsung (Ahmad, 2010; Antonius, et al., 2015; Fernandez, et al., 2019). Penerapan teknologi pengolahan citra menjadi salah satu solusi untuk monitoring kualitas paket bantuan secara daring (Islami, et al., 2017; Ilham \& Pasnur, 2018). Teknologi tersebut umum digunakan untuk mendeteksi suatu objek seperti plat kendaraan bermotor, penyakit dan kualiatas tanaman (Masdiyasa, et al., 2019; Rahmadewi \& Kurnia, 2016; Alviansyah, et al., 2017; Irtawaty \& Jayanti, 2019). Beberapa penelitian lain juga telah banyak yang membahas jenis dan kualitas beras berdasarkan data citra digital (Nurcahyani \& Saptono, 2015; Kusumanto \& Tompunu, 2011; Munantri, et al., 2019; Oktonius, et al., 2014).

Berdasarkan uraian tersebut maka pengabdian ini bertujuan untuk memperkenalkan teknologi pengolahan citra kepada Haibageur.com dalam mengidentifikasi jenis beras. Kegiatan pengabdian ini diharapkan mampu menjadi solusi dalam mengatasi permasalahan yang dihadapi Haibageur.com. Pelaksanaan kegiatan akan dilaksanakan sepenuhnya secara daring. Sebelumnya telah dilakukan kegiatan pengabdian secara daring dengan hasil yang baik (Candra, et al., 2021; Sidiq \& Irmawati, 2016; Purwandari, 2014).

\section{METODE}

Mitra dalam kegiatan pengabdian ini adalah Haibageur.com. Jumlah peserta -/+ berkisar 25 orang (pengurus/pengelola dari aplikasi tersebut). Adapun tahapan pengabdian yang dilakukan dengan pelatihan, pendampingan dan diskusi. Tahap sosialisasi merupakan tahap awal kegiatan pengabdian ini. Dimana pada tahap ini, para pengurus Haibageur.com diperkenalkan mengenai perkembangan teknologi pengolahan citra, cara pembuatan alat identifikasi, teknik pengambilan citra, serta proses pembuatan program. Kegiatan ini dilakukan secara daring menggunakan aplikasi google meet untuk menghindari kontak langsung di masa pandemi. Kegiatan sosialisasi berlangsung selama 8 jam. Kemudian ditahap kedua dilakukan proses pendampingan, dimana para pengurus Haibageur.com dibimbing untuk membuat alat, mengambil citra dan membuat program. Kegiatan pendampingan dilakukan secara daring menggunakan aplikasi whatsapps dan bersifat fleksibel tidak terbatas waktu. Adapun tahap terakhir dari kegiatan ini adalah diskusi. Pada tahap ini pengurus Haibageur.com diminta pendapatnya mengenai alat yang sudah dibuat, kemudian membahas kelebihan dan kekurangan apa saja dari alat tersebut, serta saran kedepannya dalam penerapan alat identifikasi beras di Haibageur.com. Kegiatan ini berlangsung secara daring menggunakan aplikasi google meet selama 2 jam. Maka penjabaran tahapan pelaksanaan dalama kegiatan ini sebagai berikut:

a. Pra Kegiatan, tim melakukan persiapan studi literatur untuk materi yang akan disampaikan. Berupa bahan referensi dari berbagai rujukan ilmiah. Setelah itu tim melakukan pengenalan mengenai teknologi pengolahan citra satelit. Hal ini yang akan dimanfaatkan secara optimal oleh pengurus/pengelola dari Haibageur.com. Agar memudahkan kegiatan berjalan, maka tim membuat bahan ajar berupa modul/diktat.

b. Pelaksanaan Kegiatan, tim melakukan presentasi berupa materi yang ditentukan. Selanjutnya pengurus/pengelola melakukan praktik secara langsung dengan bimbingan dari tim. Pelaksanaan berjalan dengan lancar dan sesuai konsep. Hal ini didukung oleh modul/diktat yang telah dibuat sebelumnya. Sehingga pengurus/pengelola merasa tidak kesulitan ketika mengikuti langkahlangkahnya.

c. Evaluasi dan Monitoring, tim melakukan sosialisasi secara berkala setelah selesai pelaksanaan kegiatan sebelumnya. Hasil sesuai dengan harapan, pengurus/pengelola sudah terbiasa dengan program/materi yang dijalankan. Sehingga tujuan dari kegiatan pengabdian ini adalah untuk mengidentifikasi jenis beras tercapai dengan baik.

\section{HASIL DAN PEMBAHASAN}

Kegiatan pengabdian ini dilaksanakan di masa pandemi Covid-19, sehingga seluruh proses kegiatan dilaksanakan secara daring. Kegiatan dilaksanakan secara bertahap mulai dari sosialisasi, pendampingan dan diskusi. Adapun peserta kegiatan adalah para pengurus Haibageur.com. Berikut bentuk dari Haibageur.com pada Gambar 1. di bawah ini: 


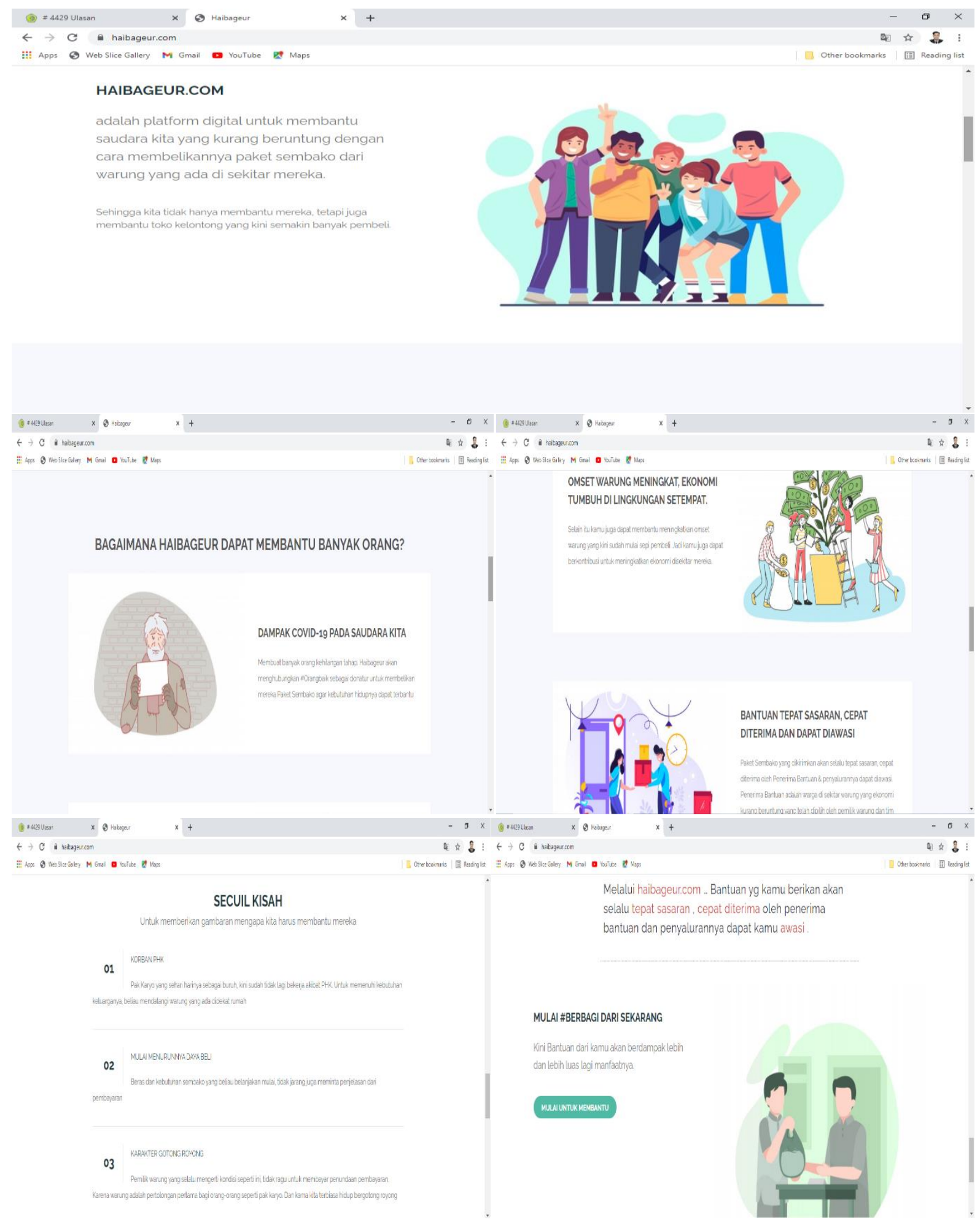

Gambar 1. Interface Haibageur.com

(Sumber : (Haibageur.com, 2021))

\section{Sosialisasi}

Setelah dilakukan sosialisasi terdapat beberapa pertanyaan mengenai teknologi pengolahan citra seperti biaya yang dibutuhkan dalam menerapkan teknologi tersebut, tingkat kesiapan teknologi dari segi pemakai dan peralatan, efektivitas penggunaan serta bagaiman cara monitoring toko klontong dengan menggunakan teknologi tersebut. Pertanyaan-pertanyaan tersebut dapat dijawab secara satu persatu dengan tepat dan lugas. Dimana dari segi biaya penerapan teknologi pengolahan citra tergantung dari peralatan yang dibutuhkan seperti alat identifikasi kamera dan komputer yang digunakan. Semakin baik peralatan yang digunakan akan semakin mahal 
pula biaya yang dikeluarkan. Kemudian dari segi kesiapan para pemakai seperti pengurus Haibageur.com dan pemilik toko klontong perlu proses pendampingan lebih lanjut dalam penggunaan alat identifikasi beras sampai ke tahap yang lebih mandiri. Selanjutnya dari segi efektivitas diperlukan banyak sampel citra beras agar akurasi alat tersebut lebih baik. Terakhir dari segi monitoring, pemilik klontong hanya perlu memberikan hasil foto beras kepada Haibageur.com. Dimana hasil foto tersebut akan diolah menggunakan computer untuk mengidentifikasi jenis dan kualitas beras tersebut.

\section{Pendampingan}

Setelah dilakukan pendampingan diketahui bahwa alat identifikasi beras menggunakan papan yang dibentuk menyerupai balok dengan ukuran $35 \mathrm{~cm} \times 35$ $\mathrm{cm} \times 25 \mathrm{~cm}$. Dimana di dalam balok tersebut diberikan penerangan menggunakan 2 buah LED berukuran 6 watt. Kemudian untuk backgroundnya menggunakan kain berwarna hitam. Setelah itu, proses pengambilan citra dilakukan dengan menyusun bulir beras dengan posisi 5 baris dan 5 kolom. Beras tersebut diambil citranya menggunakan kamera 12 megapixel. Kemudian untuk proses pembuatan program menggunakan software MATLAB dengan metode ANFIS (Adaptive Neuro Fuzzy Inference System). Berdasarkan pembuatan alat tersebut diperoleh akurasi sebesar $85,2 \%$ Keberhasilan pembuatan alat tersebut menunjukkan bahwa proses pemdampingan dapat berjalan dengan baik meskipun secara daring.

\section{Diskusi}

Berdasarkan hasil diskusi yang telah dilakukan diperoleh beberapa point. Pertama, Haibageur.com sangat mengapreasi kegiatan pengabdian ini meskipun penerapan alat identifikasi beras yang telah dibuat perlu ditingkatkan akurasinya. Kedua, teknologi pengolahan citra sangat membantu Haibageur.com dalam mengidentifikasi beras yang didistribusikan oleh toko klontong. Ketiga, masih terbatasnya kemampuan SDM dan peralatan Haibageur.com sehingga dibeberapa kegiatan masih perlu bimbingan teknis. Terakhir, perlu adanya upaya lebih lanjut terutama jika terdapat kesalahan dalam penggunaan alat. Sehingga proses pengabdian dan kemitraan dapat berjalan terus menerus. Adapun untuk manfaat dari kegiatan pengabdian kepada masyarakat ini adalah diharapkan mampu mencegah upaya manipulasi beras yang dilakukan oleh oknum pemilik toko klontong.

\section{SIMPULAN DAN SARAN}

Hasil kegiatan pengabdian masyarakat yang telah dilaksanakan ini terlihat bahwa pengurus Haibageur.com dapat mengikuti pelatihan dengan baik dan dapat langsung mempraktekkan materi yang disampaikan. Dengan adanya kegiatan ini, mampu meningkatkan pemahaman teknologi para pengurus di Haibageur.com. Penggunaan alat ini diharapkan mampu mengurangi kasus manipulasi beras di toko klontong. Adapun saran dari kegiatan ini adalah diperlukan bimbingan teknis lebih lanjut untuk. penerapan dilapangan. Hal tersebut dikarenakan kegiatan saat ini baru sebatas pengenalan dan bimbingan pembuatan alat. Saran berikutnya yaitu, diperlukan spesifikasi peralatan dan bahan yang lebih rinci agar alat yang dibuat dapat optimal.

\section{UCAPAN TERIMAKASIH}

Kami ucapkan terima kasih kepada LPPM UNSIKA yang telah memberikan dana hibah HIPSTRA dengan 1713.107/UN64/PP/2020. Kami juga ucapkan terima kasih kepada Haibageur.com yang telah bersedia menjadi mitra kami.

\section{DAFTAR RUJUKAN}

Ahmad, U., (2010). Aplikasi Teknik Pengolahan Citra dalam Analisis Non-Destruktif Produk Pangan. Rubrik Teknologi, XIX(1), pp. 71-80.

Alviansyah, F., Ruslianto, I. \& Diponegoro, M., (2017). Identifikasi Penyakit pada Tanaman Tomat Berdasarkan Warna dan Bentuk Daun dengan Metode Naive Bayes Classifier Berbasis Web. Jurnal Coding Sistem Komputer Untan, $\mathrm{V}(1)$, pp. 23-32.

Antonius, A., Triyanto, D. \& Ruslianto, I., (2015). Penerapan Pengolahan Citra dengan Metode Adaptive Motion Detection Algorithm pada Sistem Kamera Keamanan dengan Push Notification ke Smartphone Android. Jurnal Coding Sistem Komputer Untan, III(2), pp. 5465.

Candra, A. I. et al., (2021). Digital Marketing untuk Kewirausahaan Pesantren di Masa Pandemi Covid-19. Wikrama Parahita: Jurnal Pengabdian Masyarakat, V(1), pp. 1-6.

Fernandez, S., Putra, E. D. \& Sukemi, F., (2019). Terapan Teknik Pengolahan Citra Digital Mean Filtering dan Edge Detection (Canny) pada Deteksi Objek dalam Air. Jukomika - (Jurnal Ilmu Komputer dan Informatika), II(1), pp. 62-66. 
Ilham \& Pasnur, (2018). Aplikasi Pengolah Citra untuk Menentukan Jenis Tanah pada Lahan Pertanian. Inspiration: Jurnal Teknologi Informasi dan Komunikasi, VIII(2), pp. 89-96.

Irtawaty, A. S. \& Jayanti, R., (2019). Implementasi Pengolahan Citra pada Analisis Ciri Bakteri Yogurt. Jurnal Sains Terapan, II(2), pp. 83-87.

Islami, I. F., Yuwono, S. \& Nugraha, R., (2017). Implementation of Digital Image Processing for Estimating the Dimension of a Luggage on Smart Lockers Prototype. Jakarta, eProceeding of Engineering - Telkom University.

Kusumanto, R. D. \& Tompunu, A. N., (2011). Pengolahan Citra Digital untuk Mendeteksi Obyek Menggunakan Pengolahan Warna Model Normalisasi RGB. Jakarta, Seminar Nasional Teknologi Informasi \& Komunikasi Terapan 2011 (Semantik 2011).

Masdiyasa, I. G. S., Bhirawa, S. \& Winardi, S., (2019). Identifikasi Plat Nomor Kendaraan Bermotor Menggunakan Metode Multi-Step Image Processing Berbasis Android. Jurnal e-Narodroid, II(1), pp. 17-25.

Munantri, N. Z., Sofyan, H. \& F., M. Y., (2019). Aplikasi Pengolahan Citra Digital untuk Identifikasi Umur Pohon. Jurnal Telematika, XVI(2), pp. 97-104.

Nurcahyani, A. A. \& Saptono, R., (2015). Identifikasi Kualitas Beras dengan Citra Digital. Scientific Journal of Informatics, II(1), pp. 63-72.

Oktonius, Lukman \& Iskandar, R. J., (2014). Aplikasi Penerapan Pengolahan Citra Digital untuk Pengenalan Objek Menggunakan Pengembangan Metode Otsu. Jurnal InTekSis, I(3), pp. 35-45.

Poernomo, B. \& Melita, Y., (2013). Pengolahan Citra Digital untuk Pengenalan Retina dengan Jaringan Saraf Tiruan Hopfield Diskrit. Jurnal IImiah Teknologi dan Informasi ASIA, VII(1), pp. 37-47.

Priadana, A. \& Murdiyanto, A. W., (2019). Identification of Rupiah Paper Currency Denomination Using SURF and FLANN Methods at Rotation Variation. Jurnal Teknologi dan Sistem Komputer, VII(1), pp. 19-24.

Purwandari, E. P., (2014). Peningkatan Kualitas Pembelajaran Pengolahan Citra Digital pada Program Studi Teknik Informatika Menggunakan Model Project Based Learning. Jurnal Rekursif, II(1), pp. 5362.

Putri, A. R., (2016). Pengolahan Citra dengan Menggunakan Web Cam pada Kendaraan Bergerak di Jalan Raya. JIPI (Jurnal IImiah Pendidikan Informatika), I(1), pp. 1-6.

Rahmadewi, R. \& Kurnia, R., (2016). Klasifikasi Penyakit Paru Berdasarkan Citra Rontgen dengan Metoda Segmentasi Sobel. Jurnal Nasional Teknik Elektro, $\mathrm{V}(1)$, pp. 7-12.

Saputra, D. E., Rahmawati, D. \& Ibadillah, A. F., (2019). Pengolahan Citra Digital dalam Penentuan Panen Jamur Tiram. Jurnal Elektro dan Komputer Triac, $\mathrm{VI}(1)$, pp. $1-5$.

Sidiq, S. A. \& Irmawati, D., (2016). Pengolahan Citra untuk Identifikasi Telur Berdasarkan Ukuran. Journal Electronics, Informatics, and Vocational Education (ELINVO), I(3), pp. 151-156. 